\title{
EVALUASI PELAKSANAAN PEMUNGUTAN DAN PROSEDUR PENCATATAN PAJAK BUMI DAN BANGUNAN PERDESAAN DAN PERKOTAAN (PBB-P2) DI KOTA MANADO
}

\author{
Alfira Irene Imon, Harijanto Sabijono² Lidia M. Mawikere³ \\ ${ }^{1,2,3}$ Jurusan Akuntansi, Fakultas Ekonomi dan Bisnis, Universitas Sam Ratulangi, Jl. Kampus Bahu, Manado, \\ 95115, Indonesia \\ Email : irenealfira@ymail.com
}

\begin{abstract}
Land Tax and Rural and Urban Buildings (PBB-P2) is a new type of tax for regions. The enactment of Law Number 28 Year 2009, then all revenues from UN-P2 are regional rights because the process of data collection, appraisal, determination, administration, collection/collection and service of $P B B-P 2$ is held fully by local government (regency/municipality). The transfer of PBB-P2 management rights to local government is done no later than January 1, 2014. The purpose of this research is to know how the collection and recording procedure of Land and Rural Land and Urban Tax in Manado City. This type of research uses descriptive qualitative analysis method by describing the reality or the state of an object studied that is directly related in this research. The result of the research shows that the implementation of PBB-P2 collecting as local tax in Manado City has been running well and is in accordance with the existing procedures, although there are still shortcomings and obstacles in the implementation of the collection. Based on the accounting records of the Manado Regional Tax and Retribution Board of Manado has been implemented in accordance with Government Regulation No. 71 of 2010, although there is still a journal entry that is not applied because the journal entry is made by depositing income from the treasurer's cash to the local treasury and direct payment to the cash account areas conducted by the taxpayer.
\end{abstract}

Keywords : collection, recording, $P B B-P 2$

\section{PENDAHULUAN \\ Latar Belakang}

Pemerintah daerah juga di beri diskresi untuk menentukan tarif pajak yang penting artinya dalam proses desentralisasi, di mana pemerintah daerah dapat menentukan prioritas pengeluaran dan menentukan tarif daerah untuk merealisasikan penerimaan yang di inginkan sesuai dengan kebutuhan masyarakat. Selain untuk meningkatkan akuntabilitas pemerintah daerah, pengalihan PBB-P2 juga bertujuan untuk meningkatkan kinerja pemungutan pajak melalui peningkatan kualitas pelayanan kepada wajib pajak. Pemerintah daerah memiliki kewenangan penuh untuk mengolah PBB-P2 daerahnya masing-masing. Sehingga, upayaupaya peningkatan penerimaan pajak yang bersumber dari pajak bumi dan bangunan khususnya sektor perdesaan dan perkotaan dapat terus di tingkatkan, baik secara intensifikasi maupun secara ekstensifikasi.

Pengalihan kewenangan PBB-P2 sebagai pajak daerah pada Kota Manado di laksanakan mulai 1 Januari 2014, hal ini menimbulkan peluang dan tantangan tersendiri bagi pemerintah Kota Manado dalam meningkatkan pendapatan asli daerahnya. Berbagai persiapan telah di lakukan untuk melaksanakan pemungutan PBB-P2 ini seperti peraturan daerah, peraturan kepala daerah dan Standard Operating Procedure (SOP), struktur organisasi dan tata kerja, sumber daya manusia, sarana dan prasarana, kerja sama dengan pihak terkait serta pembukaan rekening pada bank yang sehat. Namun tidak dapat dihindari dalam menjalankan segala bentuk persiapan dan pelaksanaan pemungutan PBB-P2 
pemerintah Kota Manado masih menemui banyak sekali kekurangan dan hambatan baik menyangkut persoalan teknis pemungutan maupun di lapangan.

Pengalihan kewenangan PBB-P2 sebagai pajak daerah tidak hanya menyangkut soal pemungutannya saja, tetapi menyangkut proses bagaimana penerimaan PBB-P2 di catat dan di laporkan. Setiap pemerintah daerah termasuk Badan Pengelola Pajak dan Retribusi Daerah Kota Manado membuat pencatatan dan pelaporan yang menyangkut dengan penerimaan PBB-P2, dimana segala transaksi yang telah terjadi harus di catat dan di laporkan. Dengan adanya pencatatan dan pelaporan merupakan hal yang sangat penting bagi pemerintah daerah dalam mengelola keuangan daerahnya secara akuntabel dan transparan sesuai dengan peraturan perundang-undangan yang berlaku. Tujuan penelitian ini adalah untuk mengetahui bagaimana pelaksanaan pemungutan dan prosedur pencatatan Pajak Bumi dan Bangunan Perdesaan dan Perkotaan di Kota Manado.

\section{TINJAUAN PUSTAKA}

\subsection{Akuntansi}

Pengertian akuntansi menurut Weygand. et al., (2011 : 7) “Akuntansi adalah sistem informasi yang mengidentifikasi, mencatat dan mengkomunikasikan peristiwa ekonomi dari suatu organisasi kepada pihak yang memiliki kepentingan. Akuntansi adalah "In total , accounting involves the entire process of identifying, recording, and communicating economic event. Secara total, akuntansi melibatkan seluruh proses identifikasi, pencatatan dan berkomunikasi peristiwa ekonomi" (Kieso et al, 2011 : 4). Tujuan utama akuntansi adalah menyajikan informasi ekonomi (economic information) dari suatu kesatuan ekonomi (economic entity) kepada pihak-pihak yang berkepentingan. (Priyati, $2013: 1$ )

\subsection{Pajak}

Miller \& Oast (2012:3), Pajak adalah sistem pemungutan wajib atau pemerasan yang di kenakan untuk membiayai belanja publik dan juga dapat di kenakan untuk tujuan sosial dan ekonomi lainnya.Pajak adalah sistem pemungutan wajib atau pemerasan yang di kenakan untuk membiayai belanja publik dan juga dapat di kenakan untuk tujuan sosial dan ekonomi lainnya.Pajak merupakan iuran atau pungutan wajib yang dipungut oleh pemerintah dari masyarakat wajib pajak untuk menutupi pengeluaran rutin negara dan biaya pembangunan tanpa balas jasa yang dapat di tunjuk secara langsung. (Suprianto $2013: 1$ )

\subsection{Pajak Bumi dan Bangunan Perdesaan dan Perkotaan (PBB-P2)}

Menurut Siahaan (2013 : 553), Pajak Bumi dan Bangunan Perdesaan Perkotaan (PBBP2) adalah pajak atas bumi dan bangunan yang di miliki, di kuasai atau di manfaatkan oleh orang pribadi atau badan, kecuali kawasan yang di gunakan untuk kegiatan usaha perkebunan, perhutanan dan pertambangan.

\section{Pelaksanaan Pemungutan PBB-P2}

Berdasarkan Peraturan Bersama Menteri Keuangan dan Menteri Dalam Negeri Nomor 15/PMK.07/2014 dan Nomor 10 Tahun 2010 tentang Tahapan Persiapan dan Pelaksanaan Pengalihan Pajak Bumi dan Bangunan Perdesaan dan Perkotaan sebagai Pajak Daerah, pemerintah daerah bertugas dan bertanggung jawab menyiapkan hal-hal berikut ini :

1. Peraturan Daerah, Peraturan Kepala Daerah, dan SOP

2. Struktur Organisasi dan Tata Kerja

3. Sumber Daya Manusia

4. Sarana dan Prasarana

5. Kerja sama dengan pihak terkait antara lain, Kantor Pelayanan Pajak Pratama, Perbankan, Kantor Pertanahan, dan Notaris/Pejabat Pembuat Akta Tanah

6. Pembukaan rekening penampungan PBB-P2 pada bank yang sehat. 


\subsection{Penelitian Terdahulu}

Mandala Harefa (2016)dalam penelitian Kendala Implementasi dan Efektivitas Pemungutan Pajak PBB-P2 Oleh Pemerintah Kota Makassar. Hasil penelitian menunjukkan Pengalihan pemungutan PBB-P2 di laksanakan oleh Dispenda Kota Makasar dengan membentuk lembaga khusus yang berbentuk UPT. Efektivitas pemungutan PBB-P2 yang telah di lakukan oleh Dispenda Kota Makasar menunjukkan kriteria sangat efektif, namun demikian proporsi dari sisi penerimaan masih rendah.

Kurniawaty Fitri (2014) dalam penelitian Dampak Pengalihan Pengelolaan PBB-P2 Terhadap Penerimaan PBB Di Kelurahan Cinta Raja Kecamatan Sail Kota Pekanbaru. Hasil penelitian menunjukkan Kecamatan Cintaraja merupakan salah satu kecamatan dikota Pekanbaru yang selama ini selalu berhasil mencapai target penerimaan PBB.

\section{METODE PENELITIAN}

\subsection{Jenis Penelitian}

Penelitian yang di lakukan ini untuk mengetahui pelaksanaan pemungutan dan prosedur pencatatan Pajak Bumi dan Bangunan Perdesaan dan Perkotaan (PBB-P2) di Kota Manado. Jenis penelitian ini menggunakan metode deskriptif. Peneltian ini memberikan penggambaran secara sistematis mengenai unsur-unsur yang relevan melalui pandangan seseorang, organisasi, atau lainnya.

\subsection{Tempat dan Waktu Penelitian}

Penelitian di laksanakan di Badan Pengelola Pajak Dan Retribusi Daerah Kota Manado yang beralamat di Jl. Balai Kota II Tikala Kumaraka Wenang, Manado. Periode waktu penelitian di mulai pada bulan Maret-April 2017.

\subsection{Prosedur Penelitian}

Adapun keterangan yang di lakukan dari tahap-tahap Prosedur Penelitian di atas adalah sebagai berikut.:

1. Mengajukan Permohonan Penelitian

2. Pengumpulan Data

Dalam tahap ini peneliti mengumpulkan data pendukung penelitian ini denganmelakukan observasi langsung ke Badan Pengelola Pajak dan Retribusi Daerah Kota Manado, mewawancarai Kepala Bidang PBB dan BPHTB, Staf Bidang Pembukuan, dan studi dokumentasi terhadap dokumen-dokumen terkait penerapan pemungutan PBB-P2 di kota Manado.

3. Analisa Data Penelitian

Pada tahap ini di lakukan analisa data yang akan di pakai sesuai dengan judul penelitian untuk melengkapi dan menentukan hasil penelitian yang akan di ambil.

4. Kesimpulan dan Saran

\subsection{Metode Pengumpulan Data}

\section{Jenis Data}

1. Data kualitatif adalah data yang di sajikan secara deskriptif atau dalam bentuk uraian. Data kualitatif yang di gunakan dalam penelitian ini yaitu data-data yang di dapat dari wawancara yang di lakukan pada pihak yang terkait dengan penelitian ini serta bahanbahan tertulis dari objek penelitian.

2. Data kuantitatif adalah data yang di sajikan dalam bentuk angka-angka serta tabel yang di peroleh dari penjumlahan atau pengukuran.

\section{Sumber Data}

1. Data Primer adalah data yang di peroleh dari hasil wawancara yang di lakukan oleh orang yang melakukan penelitian atau yang bersangkutan yang memerlukannya dengan pihak yang terkait pada Badan Pengelola Pajak dan Retribusi Daerah Kota Manado khususnya pada Bidang PBB dan BPHTB. 
2. Data Sekunder adalah data yang diperoleh atau dikumpulkan dari sumber-sumber yang telah ada. Data sekunder di sajikan dalam bentuk tabel serta segala informasi yang berasal dari dokumen arsip instansi yang terkait, artikel dan berbagai sumber lain yang berhubungan dengan masalah penelitian ini.

\subsection{Teknik Pengumpulan Data}

Teknik pengumpulan data di lakukan dengan 2 cara, yaitu:

1. Penelitian kepustakaan (library research).

2. Penelitian lapangan (field research)

a. Teknik wawancara,

b. Metode Observasi (Pengamatan)

c. Dokumentasi.

\subsection{Metode Analisis}

Metode analisis yang di gunakan untuk membahas permasalahan dalam penelitian ini adalah metode analisis deskriptif kualitatif, yaitu dengan cara menggambarkan kenyataan atau keadaan-keadaan atas suatu objek yang di teliti dalam bentuk uraian kalimat berdasarkan keterangan-keterangan dari pihak-pihak yang berhubungan langsung dalam penelitian ini. Metode analisis ini di gunakan untuk mendeskripsikan pelaksanaan pemungutan dan pencatatan PBB-P2 di Kota Manado. Proses menganalisis di mulai dengan menganalisis penerapan pemungutan PBB-P2 yaitu tahap persiapan, tahap pelaksanaan, dan kemudian menganalisis pencatatan akuntansi PBB-P2.

\section{HASIL PENELITIAN DAN PEMBAHASAN \\ 4.1 Hasil Penelitian Pelaksanaan Pemungutan PBB-P2 \\ Tahap Persiapan}

Berdasarkan Peraturan Bersama Menkeu dan Mendagri Nomor 15/PMK.07/2014 Nomor 10 Tahun 2014 tentang Tahapan Persiapan Pengalihan PBB-P2 sebagai Pajak Daerah, maka persiapan yang perlu di lakukan oleh Pemerintah Daerah Kota Manado yaitu :

1. Peraturan Daerah, Peraturan Kepala Daerah dan Standar Operasi Prosedur (SOP)

Pemerintah Daerah Kota Manado telah menetapkan Peraturan Daerah Kota Manado Nomor 07 Tahun 2012 Tentang Pajak Bumi Dan Bangunan Perdesaan dan Perkotaan sebagai Dasar Hukum untuk melaksanakan pemungutan PBB-P2 di Kota Manado.

2. Struktur Organisasi dan Tata Kerja

Dalam rangka melaksanakan ketentuan Pasal 5 Peraturan Daerah Kota Manado Nomor 2 Tahun 2016 tentang Pembentukan dan Susunan Perangkat Daerah Kota Manado, perlu menetapkan Peraturan Walikota tentang Kedudukan, Susunan Organisasi, Tugas dan Fungsi Serta Tata Kerja Badan Pengelola Pajak dan Retribusi Daerah Kota Manado Tipe A, maka struktur organisasi yang mengelola PBB-P2 adalah Bidang Pelayanan PBB dan BPHTB.

3. Sumber Daya Manusia

a. Mengirim 10 orang aparatur untuk melaksanakan Tugas Belajar Program D-1 PBB-P2 konsentrasi Penilai dan Operator Console pada Sekolah Tinggi Akuntansi Negara (STAN) di Jakarta yang telah lulus pada November 2012.

b. Menugaskan beberapa Pegawai Negeri Sipil untuk mengikuti Bimbingan Teknis maupun Sosialisasi berkaitan dengan sistem pengelolaan Pajak Bumi dan Bangunan.

c. Menugaskan aparatur Pemerintah Kota Manado untuk Studi Banding ke beberapa daerah yang telah melaksanakan pengalihan pengelolaan Pajak Bumi dan Bangunan Perdesaan dan Perkotaan.

d. Menugaskan 19 staf bidang perimbangan untuk magang di KPP Pratama Kota Manado pada bulan April dan Mei 2013. 
e. Menugaskan 2 staf mengikuti Diklat Operator Consule di Bandung yang di adakan oleh Direktorat Jenderal Pajak Kementrian Keuangan.

4. Sarana dan Prasarana

1. Pinjam pakai gedung milik Dirjen Pajak di Jl. 17 Agustus Nomor 5

2. 1 buah server

3. 2 buah printonix

4. 15 unit computer

5. 1 buah plotter untuk cetak peta

6. 2 buah printer untuk cetak SPPT/DHKP

7. UPS

8. Alat ukur GPS Geodetic dan Total Station

9. Distance Meter

10. Kamera Digital

5. Kerja sama dengan pihak terkait yaitu KPP Pratama, Perbankan, Kantor Pertanahan dan Notaris/Pejabat Pembuat Akta Tanah

a. Kerja sama dengan Dirjen Pajak, telah di lakukan seah terima dari KPP Pratama ke Pemerintah Kota Manado, yaitu sebagai berikut.

1. Softcopy Peta PBB

2. Piutang dan asset sitaan

b. Kerja sama dengan Kantor Pertanahan

Kerja sama dengan kantor pertanahan telah di lakukan oleh Badan Pengelola Pajak dan Retribusi Daerah Kota Manado sebagai pelaksana pemungutan PBB-P2. Kerja sama yang di maksud adalah dalam hal pengurusan sertifikat tanah.

c. Kerja sama dengan Notaris

Bekerja sama dengan notaris, pihak Badan Pengelola Pajak dan Retribusi Daerah Kota Manado telah melakukannya yaitu bekerja sama dalam hal pengurusan pengalihan hak PBB-P2.

6. Pembukaan Rekening pada Bank yang Sehat

Untuk memudahkan pelaksanaan pemungutan PBB-P2, pihak Badan Pengelola Pajak dan

Retribusi Daerah Kota Manado saat ini telah melakukan kerja sama dengan pihak bank yaitu Bank Sulut.

\section{Tahap Pelaksanaan}

Pelaksanaan pemungutan PBB-P2 di Kota Manado mulai di laksanakan pada 1 Januari 2014.Pendataan objek PBB-P2 di lakukan oleh subjek pajak dengan mengisi Surat Pemberitahuan Objek Pajak (SPOP).sebagaimana dimaksud pada ayat (1) dapat dilakukan dengan alternatif yaitu penyampaian dan pemantauan pengembalian SPOP,identifikasi objek pajak,verifikasi data objek pajak,pengukuran bidang objek pajak. SPOP harus di isi dengan jelas, benar dan lengkap serta di tandatangani oleh subjek pajak dan di sampaikan ke Badan Pengelola Pajak dan Retribusi Daerah paling lambat 30 (tiga puluh) hari setelah tanggal di terimanya SPOP oleh subjek pajak atau kuasanya.

Penilaian dan penetapan objek pajak baru PBB-P2 yang di lakukan oleh Badan Pengelola Pajak dan Retribusi Daerah Kota Manado saat ini adalah melalui CAV (Computer Assisted Valuation) yang adalah proses penilaian dengan bantuan komputer dengan kriteria yang sudah di tentukan dan perekaman pendataan dan pendaftaran subjek/objek PBB-P2 di input ke dalam sistem atau basis data spesial yang di lakukan oleh Operator Consule. Dalam pemungutan Badan Pengelola Pajak dan Retribusi Daerah juga melakukan kegiatan penagihan yaitu penagihan aktif. Penagihan aktif merupakan kegiatan tindakan pelaksanaan penagihan sejak tanggal jatuh tempo pembayaran sampai dengan pengajuan permintaan penetapan tanggal dan tempat pelelangan meliputi jangka waktu 58 hari. 


\section{Pencatatan Akuntansi PBB-P2}

Pencatatan jurnal untuk pendapatan PBB-P2 di Badan Pengelola Pajak dan Retribusi

Daerah Kota Manado adalah sebagai berikut :

1. Pada saat menerima pendapatan

Kas di Bendahara Penerimaan $\quad$ xxx

Pendapatan PBB

2. Pada saat mengeluarkan tagihan kepada masyarakat (Wajib Pajak)

Piutang PBB

Pendapatan PBB

$\mathrm{xxX}$

$\mathrm{XXX}$

3. Pada saat Wajib Pajak membayar hutang pajak

Kas di Bendahara Penerimaan

Piutang PBB

XXX

$\mathrm{XXX}$

\subsection{Pembahasan}

\section{Pelaksanaan Pemungutan PBB-P2}

Dalam melaksanakan pemungutan Pajak Bumi dan Bangunan Perdesaan dan Perkotaan (PBB-P2), pihak Badan Pengelola Pajak dan Retribusi Daerah Kota Manado selaku pengelola Pajak Bumi dan Bangunan Perdesaan dan Perkotaan telah melakukan segala upaya dalam menyusun berbagai persiapan yang berkaitan dengan pemungutan Pajak Bumi dan Bangunan Perdesaan dan Perkotaan sesuai dengan ketentuan perundang-undangan yang berlaku yaitu dengan adanya peraturan Daerah Kota Manado Nomor 07 Tahun 2012 tentang Pajak Bumi dan Bangunan Perdesaan dan Perkotaan (PBB-P2) dan Peraturan Walikota Manado tentang Tata Cara Pemungutan Pajak Bumi dan Bangunan Perdesaan dan Perkotaan (PBB-P2). Penerapan pemungutan pajak tidak hanya di lihat dari wajib pajak dalam melaksanakan kewajiban mereka tetapi juga di lihat dari kinerja aparatur pajak dalam mereka melaksanakan pemungutan pajak tersebut. Pemungutan PBB-P2 di Kota Manado sudah mulai di laksanakan pada tanggal 1 Januari 2014. Adanya kerja sama dengan dinas, kecamatan dan kelurahan akan menjadi awal yang baik dalam penerapan pemungutan PBB-P2, tentunya juga akan berdampak pada hubungan antara pemerintah dan masyarakat sebagai wajib pajak.

Secara umum, penerapan pemungutan PBB-P2 di Kota Manado sudah berjalan baik, tetapi masih tetap terdapat hambatan-hambatan yang tidak dapat di hindari. Adapun hambatan-hambatan yang terjadi yaitu seperti data yang belum ter-update, peta kelurahan, blok, Zona Nilai Tanah (ZNT) dan bidang yang belum lengkap, Sistem Informasi Geografis belum lengkap dan mutakhir, belum adanya teknisi IT, Generator Set yang rusak karena banjir, yang jika terjadi pemadaman listrik bisa menyebabkan gangguan server PBB dan personil yang masih kurang. Hambatan yang terjadi di lapangan adalah kesadaran wajib pajak dalam membayar pajak khususnya untuk wajib pajak yang mempunyai tunggakan pajak dalam jumlah yang sedikit. Meskipun sudah berulang kali di berikan surat peringatan, sering kali hanya di abaikan oleh wajib pajak. Itulah kendala yang terjadi dalam proses pemungutan PBB-P2.

Jadi di lihat dari semua persiapan Badan Pengelolan Pajak dan Retribusi Daerah Kota Manado dalam pelaksanaan PBB-P2 sudah tersusun dengan baik, struktur organisasi yang sudah mempunyai bidang PBB dan BPHTB yang secara khusus mempunyai tugas untuk menangani pemungutan PBB-P2 juga Peraturan Walikota yang berisi petunjuk teknis pelaksanaan pemungutan berupa Standar Operasional Prosedur (SOP), sudah adanya Sumber Daya Manusia yang khusus mengelola PBB-P2 seperti tenaga penilai yang terdiri dari 3 (tiga) orang dan operator console, juga BP2RD Kota Manado juga sudah menggunakan Sistem Manajemen Informasi Objek Pajak (SISMIOP) untuk lebih memudahkan proses pengelolaan administrasi PBB-P2. 


\section{Prosedur Pencatatan PBB-P2}

Pemerintah daerah di tuntut dapat memberikan laporan keuangan yang baik dan benar harus sesuai dengan ketentuan yang berlaku. Peraturan Pemerintah Nomor 71 Tahun 2010 tentang Standar Akuntansi Pemerintahan (SAP) yang akan di gunakan untuk menghasilkan suatu laporan keuangan yang dapat di jadikan acuan dalam pengambilan keputusan dalam lingkup pemerintahan termasuk pemerintahan daerah. Pengakuan Pendapatan untuk PBB-P2 di dahului dengan adanya penetapan oleh Fiskus pajak terlebih dahulu (official assessment). Pencatatan pendapatan merupakan peranan penting dalam melakukan proses akuntansi selanjutnya sehingga dapat menghasilkan output yaitu laporan keuangan. Dari pencatatan pendapatan inilah dapat di nilai apakah suatu pemerintahan daerah sudah akuntabel dan transparan dalam mengelola keuangan daerahnya.

Prosedur pencatatan akuntansi untuk PBB-P2 yang seharusnya sesuai dengan Peraturan Pemerintah Nomor 71 Tahun 2010, yaitu sebagai berikut.

1. Saat Dinas Pendapatan mengeluarkan Surat Pemberitahuan Pajak Terutang (SPPT) kepada wajib pajak

Piutang PBB

Pendapatan PBB-LO

$\mathrm{XXX}$

(Jurnal LO atau Neraca)

$\operatorname{XXX}$

2. Saat menerima pembayaran atas PBB

Kas di Bendahara Penerimaan

Piutang PBB

XXX

(Jurnal LO atau Neraca)

Perubahan SAL

Pendapatan PBB-LRA

XXX

(Jurnal LRA)

3. Untuk penyetoran pendapatan ke kas daerah

$\mathrm{R} / \mathrm{K}$ PPKD

Kas di bendahara penerimaan

XXX

(Jurnal LO atau Neraca)

4. Jika wajib pajak melakukan pembayaran langsung ke rekening kas daerah

$\mathrm{R} / \mathrm{K}$ PPKD

Piutang PBB

XXX

(Jurnal LO atau Neraca)

Perubahan SAL

XXX

Pendapatan PBB-LRA

XXX

(Jurnal LRA)

\section{PENUTUP}

\subsection{Kesimpulan}

Tujuan dari penelitian adalah untuk mengevaluasi dan mengetahui bagaimana pelaksanaan PBB-P2 sebagai pajak daerah di Kota Manado khususnya mengenai pemungutan dan untuk mengetahui bagaimana prosedur pencatatan PBB-P2 di pemerintahan Kota Manado. Berdasarkan hasil penelitian dan pembahasan pada bab-bab sebelumnya maka dapat di tarik suatu kesimpulan bahwa penerapan pemungutan PBB-P2 di Kota Manado sudah berjalan dengan baik dan sudah sesuai dengan prosedur yang ada, meskipun masih terdapat kekurangan dan hambatan dalam pelaksanaan pemungutan yang terjadi di kantor maupun yang terjadi di lapangan..

Berdasarkan pencatatan akuntansi, dapat di simpulkan bahwa pencatatan akuntansi untuk PBB-P2 yang di buat oleh Badan Pengelola Pajak dan Retribusi Daerah Kota Manado 
sudah di terapkan sesuai dengan pencatatan akuntansi menurut Peraturan Pemerintah Nomor 71 Tahun 2010, meski masih terdapat ayat jurnal yang tidak di terapkan oleh Badan Pengelola Pajak dan Reribusi Daerah Kota Manado karena ayat jurnal tersebut di lakukan penyetoran dari bendahara penerimaan ke kas daerah dan pembayaran langsung yang di lakukan oleh wajib pajak ke rekening kas daerah bukan lagi melalui kantor.

\subsection{Saran}

1. Perlu di lakukan penyempurnaan terhadap hal-hal yang masih menjadi kendala dalam pemungutan pajak seperti melengkapi sarana dan pra-sarana yang di butuhkan serta mengupdate data wajib pajak. Apabila melakukan pendataan terhadap objek/subjek pajak baru sebaiknya bukan hanya pendataan pasif saja tetapi juga pendataan aktif agar data yang di hasilkan lebih dapat di percaya dan sesuai dengan keadaan yang sebenarnya.

2. Kualitas dan kuantitas SDM yang mengelola PBB-P2 perlu di tingktkan lagi, jumlah aparatur yang perlu untuk di tambah lagi karena jumlah yang ada saat ini masih kurang. Dengan meningkatnya pelayanan aparatur terhadap masyarakat (wajib pajak) maka tingkat kepuasaan dan kepatuhan wajib pajak akan meningkat pula.

3. Badan Pengelola Pajak dan Retribusi Daerah Kota Manado perlu mengadakan sosialisasi mengenai pemungutan PBB-P2 agar masyarakat (wajib pajak) mengerti, sehingga masyarakat mau dan patuh untuk membayar pajak.

\section{DAFTAR PUSTAKA}

Febrianto, Donny. 2013. Evaluasi Pengendalian Intern Atas Sistem Pemungutan Pajak Bumi Dan Bangunan Perdesaan Dan Perkotaan (Studi Pada Dinas Pendapatan Pengelolaan Keuangan Dan Aset Kabupaten Malang).

Fitry, Kurniawaty. 2014. Dampak Pengalihan Pengelolaan PBB - P2 Terhadap Penerimaan PBB Di Kelurahan Cinta Raja Kecamatan Sail Kota Pekanbaru.

Harefa, Mandala. 2016. Kendala Implementasi Dan Efektivitas Pemungutan Pajak PBB-P2 Oleh Pemerintah Kota Makassar.

E. Kieso, Donald, Jerry J. Weygandt and Teery D. Warfield. 2011. Intermediate Accounting. Edisi 12 by : Erlangga.

Miller, Angharad and Lynne Oast. 2012. "Principles of Imternational Taxation"

Pemerintah Republik Indonesia. Undang-Undang Nomor 28 Tahun 2007 tentang Ketentuan Umum dan Tata Cara Perpajakan. Jakarta

Pemerintah Republik Indonesia, Peraturan Bersama Manteri Keuangan dan Menteri Dalam Negeri Republik Indonesia Nomor 15/PMK.07/2014 dan Nomor 10 Tahun 2014 tentang Tahapan Persiapan dan Pelaksanaan Pengalihan Pajak Bumi dan Bangunan Perdesaan dan Perkotaan sebagai Pajak Daerah

Pemerintah Republik Indonesia, Undang-Undang Nomor 34 Tahun 2000 Perubahan Atas Undang_Undang Nomor 18 Tahun 1997 tentang "Pajak Daerah dan Retribusi Daerah"

Pemerintah Republik Indonesia, Peraturan Pemerintah Nomor 71 Tahun 2010 Tentang Standar Akuntansi Pemerintahan

Priyati, Novi. 2013. Pengantar Akuntansi. Penerbit Indeks. Jakarta

Reeve, Warren, Duchac, Suhardianto, Kalanjati, Jusuf dan Djakman. 2011. Indonesia Adaptation Principles of Accounting, $2^{\text {nd }}$ Edition Volume 1, Penerbit Salemba Empat. Jakarta

Siahaan, Marihot. 2013. Pajak Daerah dan Retribusi Daerah. Edisi Revisi. PT. Raja Grafindo Persada. Jakarta. 
Suprianto. 2013. Hukum Pajak Indonesia. Graham Ilmu. Jakarta.

Weygandt, Kimmel, dan Kieso. 2011. Financial Accounting IFRS Edition, Penerbit John Wiley Sons, Inc.

Wijayanto, Arief, 2013. PBB sebagai Pajak Daerah. Artikel. 